AIAA-2001-1602

\title{
IMPACT TEST AND SIMULATION OF ENERGY ABSORBING CONCEPTS FOR EARTH ENTRY VEHICLES
}

\author{
Marcus D. Billings* \\ The George Washington University, Joint Institute for Advancement of Flight Sciences \\ Hampton, VA \\ Edwin L. Fasanella ${ }^{+}$ \\ US Army Research Laboratory, Vehicle Technology Directorate \\ Hampton, VA \\ Sotiris Kellas ${ }^{\ddagger}$ \\ Veridian Systems \\ Yorktown, VA
}

\begin{abstract}
Nonlinear dynamic finite element simulations have been performed to aid in the design of an energy absorbing concept for a highly reliable passive Earth Entry Vehicle (EEV) that will directly impact the Earth without a parachute. EEV's are designed to return materials from asteroids, comets, or planets for laboratory analysis on Earth. The EEV concept uses an energy absorbing cellular structure designed to contain and limit the acceleration of space exploration samples during Earth impact. The spherical shaped cellular structure is composed of solid hexagonal and pentagonal foam-filled cells with hybrid graphiteepoxy/Kevlar cell walls. Space samples fit inside a smaller sphere at the center of the EEV's cellular structure. Comparisons of analytical predictions using MSC.Dytran with test results obtained from impact tests performed at NASA Langley Research Center were made for three impact velocities ranging from 32 to $40 \mathrm{~m} / \mathrm{s}$. Acceleration and deformation results compared well with the test results. These finite element models will be useful for parametric studies of off-nominal impact conditions.
\end{abstract}

\section{Introduction}

An Earth Entry Vehicle (EEV) is designed to return materials from asteroids, comets, or planets to Earth. A current concept for an EEV is a circular aeroshell structure approximately one meter in diameter with an energy absorbing impact sphere in the center of the vehicle. A simple, highly reliable, and cost-effective EEV would be a vehicle that has a direct entry to Earth and can withstand a terminal velocity land impact without a parachute'. Thus, an optimal impact surface for an EEV would be soft clay soil ${ }^{2}$. Design criteria for the EEV concept require that sample containment be assured with high levels of reliability. Thus, an energy absorbing impact sphere has been designed to limit the acceleration of the samples and to provide a high level of containment to increase reliability. A concept for the EEV and the system components is shown in Figure 1.

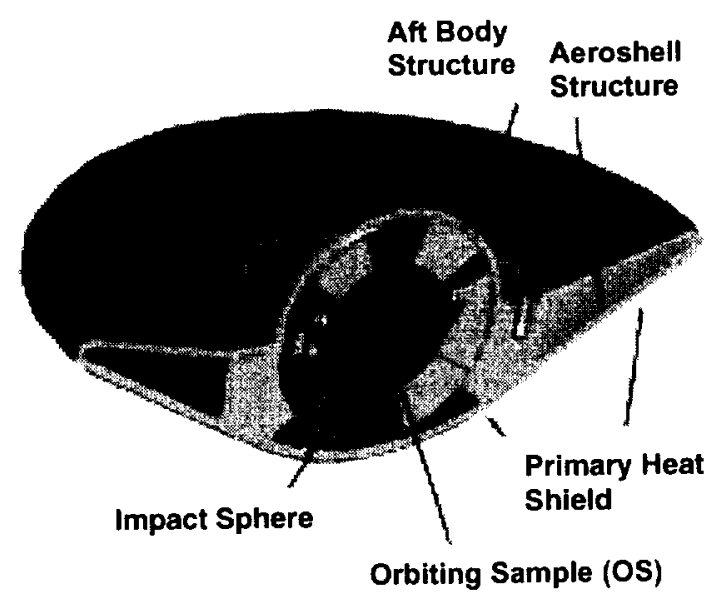

Figure 1 - Schematic of candidate Earth Entry Vehicle.

- Graduate Research Scholar Assistant, NASA Langley Research Center. Student Member AIAA, ASME.

+ Structural Dynamics Branch, NASA Langley Research Center. Member AHS.

: Principal Engineer.

This paper is declared a work of the U.S. Government and is not subject to copyright protection in the United States.

1 
The current concept of the energy absorbing impact sphere is a composite cellular structure made with energy absorbing materials that will limit the acceleration of the samples and ensure containment. The cellular structure is composed of cells that are filled with energy absorbing foams and enclosed with hybrid composite cell walls. Energy absorbing materials include carbon foam, Kevlar, graphite, and hybrid Kevlar-graphite composites. Rock, soil, and atmospheric samples may be kept within the cellular structure in a sample container designated the Orbiting Sample (OS).

In order to meet the required reliability and containment assurance criteria, nonlinear dynamic finite element simulations of the impact of the EEV's cellular structure onto a rigid surface are being performed. These simulations will serve as an aid in the design and testing phase of the program. The purpose of the simulations is to calculate accelerations and deformations of the cellular structure and compare with experimental data. Once confidence in the model is achieved, off nominal impact conditions could be simulated that would otherwise prove to be difficult and costly to perform. These simulations are executed using the commercial nonlinear dynamic finite element code MSC.Dytran ${ }^{3}$.

The objective of this paper is to describe the modeling and simulation of the EEV cellular structure and to show comparisons of experimental data with analytical results. Each model created for the analysis will be described and compared with experimental data from the corresponding drop test performed at NASA Langley Research Center's Impact Dynamics Research Facility (IDRF).

\section{Cellular Structure}

A series of impact drop tests of cellular structure test specimens were conducted at the IDRF to optimize energy absorption and to protect the $\mathrm{OS}^{4}$. The design criterion requires that the peak acceleration of the OS be limited to approximately $3,500 \mathrm{~g}$ 's on a hard surface impact. Additionally, the cellular structure must protect the OS by not crushing completely on impact. For each test, variations were made to cell wall thickness, foam density, or OS size and shape. The cross section of a typical drop test specimen is shown in Figure 2.

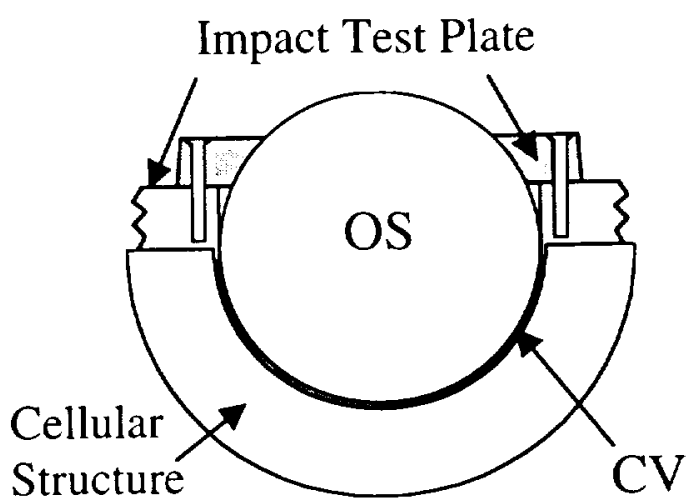

Figure 2 - Typical experimental drop test specimen.

The current drop test specimen is a hemisphericalshaped structure with six pentagonal shaped cells, five hexagonal shaped cells, and ten cells that are partially hexagonal shaped. The bottom view of a typical cellular structure is shown in Figure 3, which illustrates how the individual cells are assembled to form the complete cellular structure.

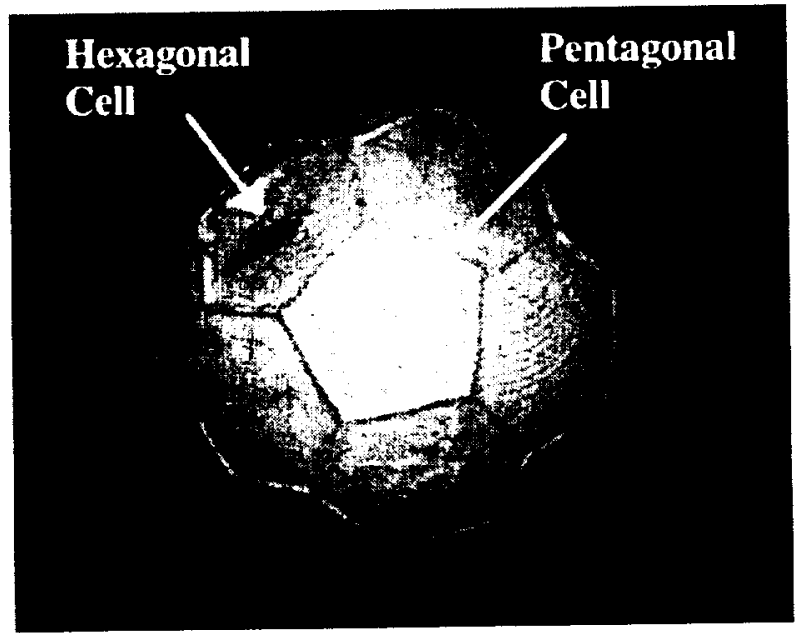

Figure 3 - Bottom view of cellular structure showing shape and geometry of the cells.

Each foam-filled cell has hybrid composite graphiteepoxy/Kevlar cell walls. The graphite-epoxy laminate provide stiffness and strength, while the Kevlar layers provide post-test structural integrity to the cell walls. Polyurethane foam was used initially to demonstrate the concept. It was later replaced with carbon foam, which was used sparingly due to high cost. The outer surface of the spherical cellular structure is wrapped in Kevlar, while the inner surface, which supports the OS, is constructed of a graphite-epoxy laminate. Between the larger spherical cellular structure and the $O S$ are several 
layers of Kevlar, which is called the Containment Vessel (CV). The Kevlar is laid inside the cellular structure to provide containment of the OS material and penetration resistance from foreign objects during impact. The OS is a sphere and will contain materials collected from exploration missions; i.e., rock, soil, and atmospheric samples. Advanced concepts include a titanium canister inside the spherical OS that holds the collected samples. Surrounding the titanium canister will be foam that protects the samples over the course of the mission. An impact test plate has also been added to the drop test specimen and represents mass associated with the top half of the cellular structure, which was not constructed for the impact test program. The components of a drop test specimen can be viewed in Figure 4. A picture of an experimental setup is shown in Figure 5 .

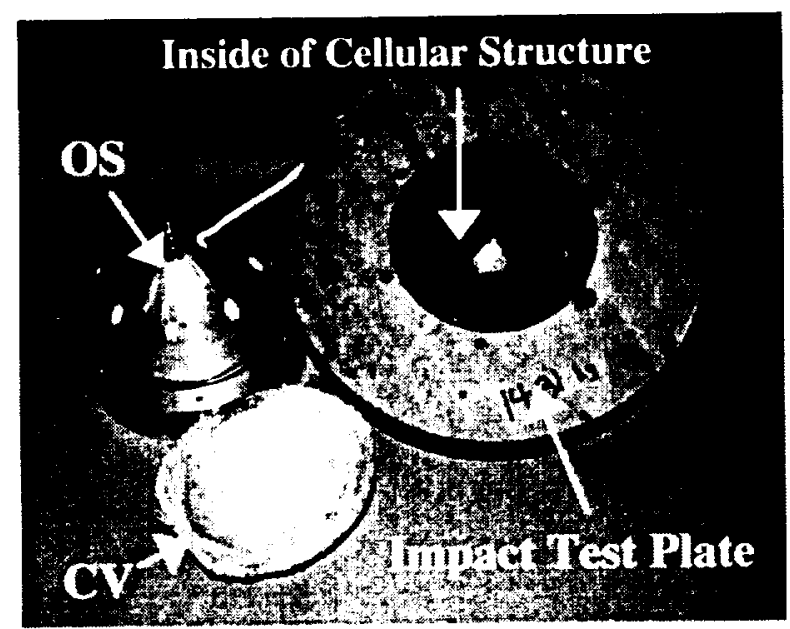

Figure 4 - Picture showing components of drop test specimen with aluminum $O S$.

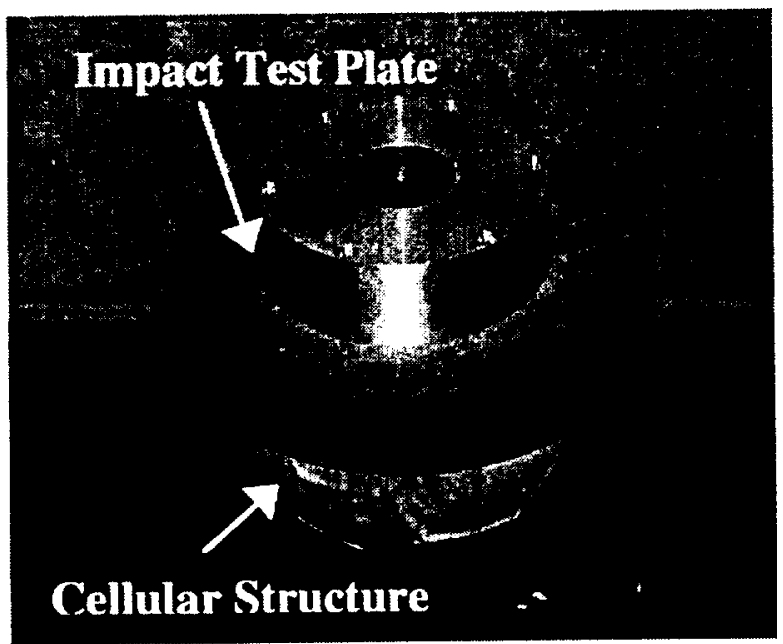

Figure 5 - Picture of typical experimental setup with OS located within cellular structure.

\section{Drop Tests at Impact Dynamics Research Facility}

The initial tests of the cellular structure were simple instrumented drop tests from the 80 meter high gantry structure at the IDRF ${ }^{5}$. Test specimens were released from $60 \mathrm{~m}$ above the concrete impact surface, which resulted in impact velocities up to $34 \mathrm{~m} / \mathrm{s}$. A picture of the gantry is shown in Figure 6. Recently, a bungee assisted accelerator system has been designed and constructed at the IDRF gantry to produce impacts up to $45 \mathrm{~m} / \mathrm{s}$, the expected terminal velocity of this EEV concept. A diagram of the bungee accelerometer is illustrated in Figure 7. In this paper, three separate impact tests will be described illustrating development of the cellular structure concept. Table 1 outlines the three drop-tests described with pertinent test parameters provided

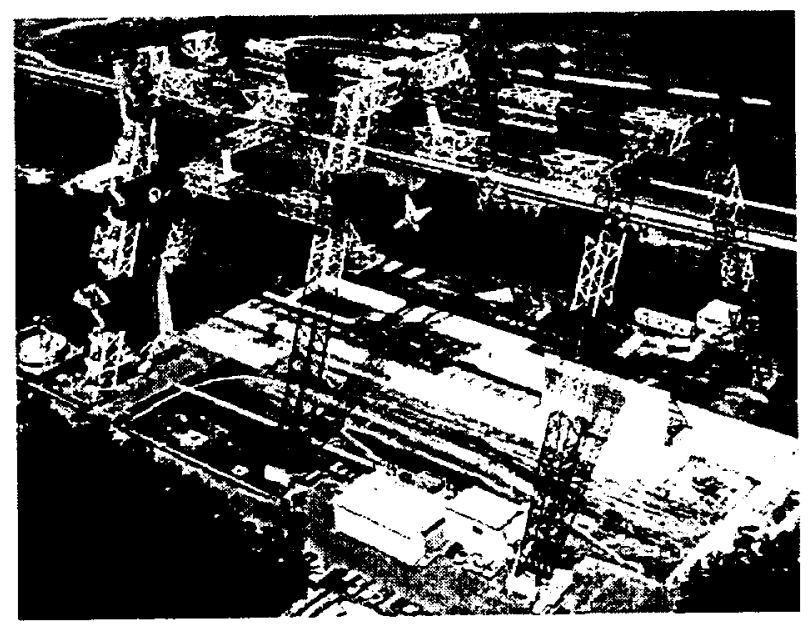

Figure 6 - IDRF at NASA Langley Research Center.

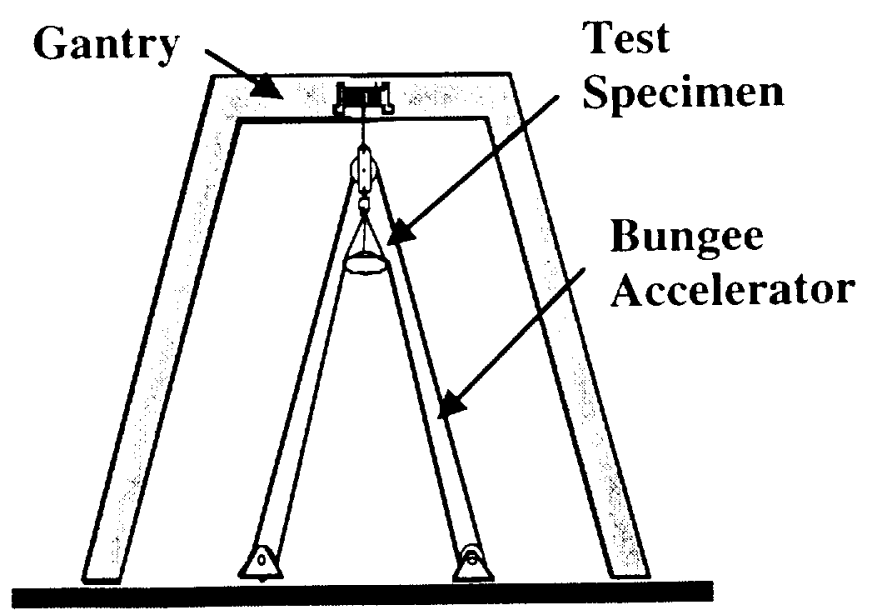

Figure 7 - Schematic drawing of bungee accelerator located under gantry structure. 
Table 1 - Impact parameters of drop test specimens.

\begin{tabular}{|c|c|c|}
\hline $\begin{array}{c}\text { Drop } \\
\text { Model }\end{array}$ & $\begin{array}{c}\text { Total Mass } \\
(\mathrm{kg})\end{array}$ & $\begin{array}{c}\text { Impact Velocity } \\
(\mathrm{m} / \mathrm{s})\end{array}$ \\
\hline 1 & 9.816 & 32.00 \\
\hline 2 & 12.381 & 35.52 \\
\hline 3 & 14.310 & 40.40 \\
\hline
\end{tabular}

\section{Nonlinear Dynamic Finite Element Code}

The analysis was performed using the software code MSC.Dytran Version 2000. MSC.Dytran is an explicit, nonlinear transient dynamic finite element computer code used for analyzing solid components, structures and fluids ${ }^{3}$. The code offers a library of relatively simple structural elements including beams, shells, and solids for modeling complex structures. MSC.Dytran also offers a variety of material models for elastic, elastic-plastic, layered orthotropic, crushable foams, and soils; thereby allowing many engineering material systems to be analyzed. Several modeling options are available for contact, impact, and penetration including breakable joints and element erosion. Automatic time step control is provided once the user defines an acceptable initial time step. Archive files for postprocessing deformed shapes and time history files must be requested by the user in advance. A restart capability is also provided.

\section{Impact Simulation \#1}

The initial drop test specimen was used to establish a method for dynamic testing of the cellular structure concept. The test also validated the design of the concept and provided information for the design of future cellular structure concepts. The specimen was dropped from the gantry at a height of $60 \mathrm{~m}$ above the concrete surface, which provided an estimated impact speed of $34 \mathrm{~m} / \mathrm{s}$. The total mass of the cellular structure, $\mathrm{CV}$, and $\mathrm{OS}$ for the first drop test was 9.816 $\mathrm{kg}$. The cellular structure had an outside diameter of $0.317 \mathrm{~m}$ and an inside diameter of $0.180 \mathrm{~m}$, resulting in a cell height of $0.080 \mathrm{~m}$. The thickness of the $C V$ was approximately $0.0056 \mathrm{~m}$. Two accelerometers were used to capture the acceleration pulse. One accelerometer was mounted inside the drop test specimen to determine the OS response, and the second was mounted on top of the impact test plate. In addition, high speed film and digital video was used to capture the impact. The actual impact velocity was determined from the low-g accelerometer and highspeed film of the event and was found to be approximately $32 \mathrm{~m} / \mathrm{s}$.
Finite Element Model

To simulate the initial drop test, a simplified model was created from provided geometry. The major components of the drop test specimen are the cellular structure, the $\mathrm{CV}$, and the OS. The components of the cellular structure are the energy absorbing foam, hybrid composite cell walls, the inner graphite-epoxy layer, and the outer Kevlar layer. The CV and OS are defined separately. The sample containing OS that is within the cellular structure was represented by rigid body shell elements located on top of the CV. Concentrated masses were applied at various locations across the top of the cellular structure to model the impact test plate, which represents the top half of the energy absorbing cellular structure. A rigid impact surface was modeled with shell elements. The discretized model that was used to simulate the initial drop test at the IDRF is shown in Figure 8. An exploded view of the model showing the three major components of the drop model is presented in Figure 9. Additionally, a detailed crosssection of the cellular structure discretization is shown in Figure 10

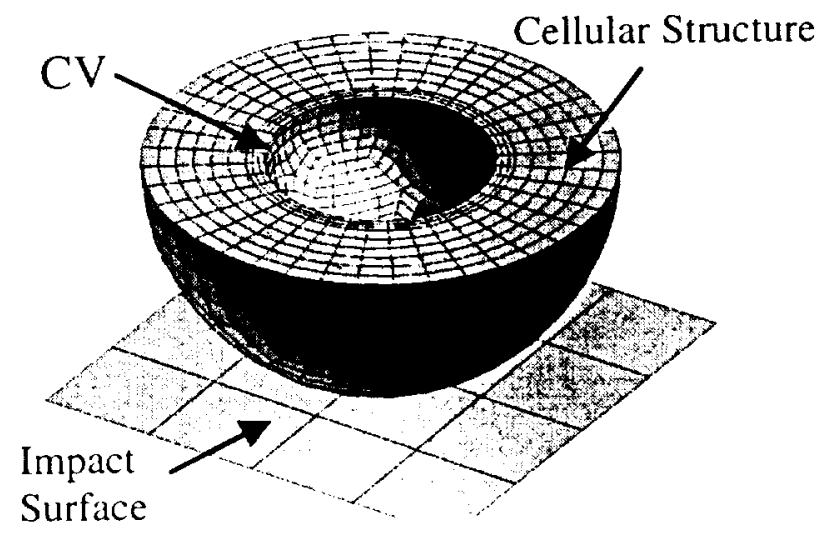

Figure 8-Dynamic F.E. model of test specimen.

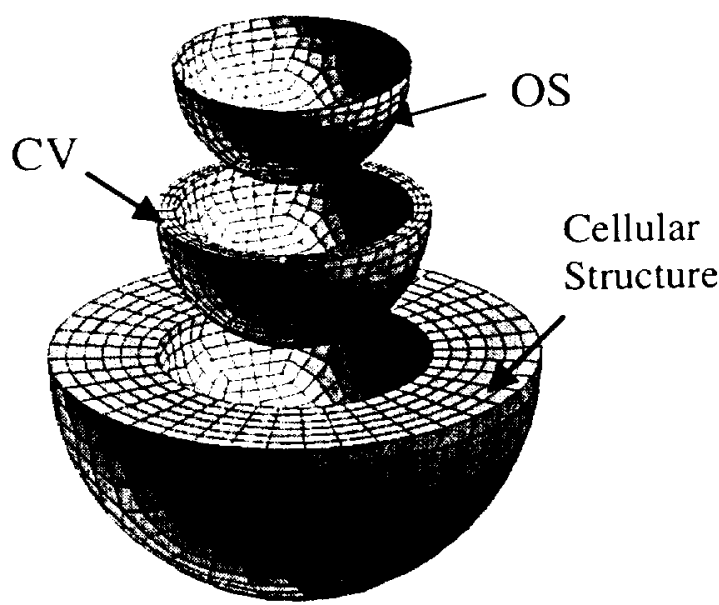

Figure 9 - Exploded view of analytic F.E. model used to simulate the impact drop test. 


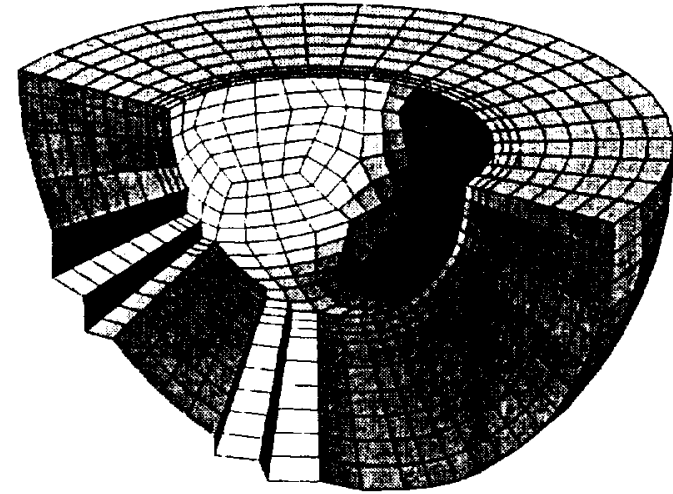

Figure 10 - Discretized cross section of test specimen.

The MSC.Dytran model contained 4,635 grid points and 6,616 elements. The model consisted of seven groups of elements, including the foam in each cell, the $\mathrm{CV}$, the graphite-epoxy/Kevlar cell walls, the outer and inner surface of the cellular structure, the rigid body $O S$, and the impact surface.

The polyurethane foam was modeled with 2,640 8noded Lagrangian solid elements. The material model for these elements was an isotropic, elastoplastic material model with a yield stress defined to allow for plastic deformation. In this analysis, isotropic material properties were defined for the foam based on experimental results from testing foam core samples. The density $\rho$ was determined to be $85.78 \mathrm{~kg} / \mathrm{m}^{3}$, the Young's modulus E was $1.982 \times 10^{7} \mathrm{~Pa}$, the Poisson's ratio $\vee$ was 0.3 , and the yield stress was $1.034 \times 10^{6} \mathrm{~Pa}$.

The $C V$ was represented by 1,320 8-noded Lagrangian solid elements, with three elements defined through the thickness of the CV. For each solid element, there is one integration point, which is located at the center of the element. Thus, to accurately predict the stress distribution through the thickness of the $\mathrm{CV}$, three integration points, and three elements, are needed. The material model for these elements is an isotropic, elastoplastic model where the values were determined based on the properties of Kevlar. The Young's modulus $E$ was $7 \times 10^{10} \mathrm{~Pa}$, the Poisson's ratio $V$ was 0.3 , and a value of $3.44 \times 10^{7} \mathrm{~Pa}$ was used for the yield stress. The $C V$ density was determined by dividing the mass of the $\mathrm{CV}$ by the calculated volume from the finite element code. This density $\rho$ was found to be 383 $\mathrm{kg} / \mathrm{m}^{3}$.

To model the graphite-epoxy/Kevlar cell walls, 1,320 4-noded Lagrangian shell elements were used with an isotropic, elastic-plastic material with a user specified shell thickness of $0.003048 \mathrm{~m}$. In this analysis, the equivalent isotropic material properties for the cell walls were extracted from tensile test data test coupons, which represented the quasi-isotropic lay-up of the cell walls. The Young's modulus E was $1.379 \times 10^{10} \mathrm{~Pa}$, the Poisson's ratio $v$ was 0.3 , a value of $1.379 \times 10^{8} \mathrm{~Pa}$ was used for the yield stress, and the density $\rho$ was found to be $1,539 \mathrm{~kg} / \mathrm{m}^{3}$.

The outer hemispherical surface of the cellular structure was wrapped with Kevlar sheets and modeled with an isotropic, elastoplastic material model with 440 4noded shell elements. For the set of elements, the defined thickness was measured to be $0.0005 \mathrm{~m}$. The density $\rho$ was $1,379 \mathrm{~kg} / \mathrm{m}^{3}$, the Young's modulus E was $6.895 \times 10^{9} \mathrm{~Pa}$, the Poisson's ratio $v$ was 0.3 , and the yield stress was $1.034 \times 10^{8} \mathrm{~Pa}$.

The inner surface of the cellular structure was a laminate composite of graphite-epoxy and was represented by 440 4-noded shell elements with an equivalent isotropic, elastoplastic material model. For the set of elements, the defined thickness of the shells was measured to be $0.000762 \mathrm{~m}$. The density $\rho$ was $1,550 \mathrm{~kg} / \mathrm{m}^{3}$, the Young's modulus $\mathrm{E}$ was $4.55 \times 10^{10} \mathrm{~Pa}$, the Poisson's ratio $v$ was 0.3 , and the yield stress was $5.79 \times 10^{8} \mathrm{~Pa}$.

The OS was modeled using 4404 -noded Lagrangian shell elements located on the inner surface of the $\mathrm{CV}$. These elements were defined as a rigid body and represented the mass and inertia associated with the OS. In the drop test specimen, the OS was represented by ballast that filled the inner volume of the impact sphere. To represent the OS mass in the model, the rigid body shell elements were defined to have the center of gravity (CG) that matched the CG of the ballast with the proper moments of inertia. On the MATRIG material card, the mass of the OS was defined as $3.9 \mathrm{~kg}$ with an initial impact velocity of $32 \mathrm{~m} / \mathrm{s}$.

The impact surface was modeled using sixteen 4-noded Lagrangian shell elements with a thickness of approximately $1 \mathrm{~m}$. The material model for these elements was an isotropic elastic-plastic model with a large value for Young's modulus ( $E$ of $6.895 \times 10^{10} \mathrm{~Pa}$ ) to approximately represent the concrete impact surface at the IDRF. The inpact surface is represented this way to avoid numerical difficulties in the contact algorithm when a surface is defined as rigid.

Included in the model were ten concentrated masses distributed around the top of the cellular structure. These masses represented the weight associated with the impact test plate, which represented the top half of the cellular structure. Each lumped mass was $0.440 \mathrm{~kg}$. 
The contact defined between the cellular structure and the impact surface was modeled using the penalty method. In the analysis, shell elements from the modeled impact surface were the master surface and all nodes of the cellular structure were defined as slave nodes. At the beginning of the analysis, the cellular structure is positioned approximately one millimeter above the impact surface. This method ensures no initial penetration of slave nodes into the master surface upon starting the simulation.

\section{Numerical Results}

All finite element simulations were performed using the MSC.Dytran Version 2000 finite element code. The time step for the impact simulation stabilized at 0.1593 microseconds. The simulated impact was run for 0.004 $s$ to ensure that the complete acceleration pulse was captured. After this time, the cellular structure begins to rebound and the simulation is terminated. The finite element simulation took approximately three CPU hours on a Sun Ultra Enterprise 450 engineering workstation.

Data from the OS accelerometer was compared to the analytical acceleration response of the rigid body OS in Figure 11. The data from the OS accelerometer was filtered with a $2500 \mathrm{~Hz}$ low pass filter. The numerical simulation of the impact determined that the OS experienced a peak acceleration of approximately 2,900 g's. The experimental peak acceleration of the OS was $2,560 \mathrm{~g}$ 's. Although the analytical peak value was slightly high, the overall shape and duration of the acceleration curve compared favorably to the experimental acceleration curve.

\section{Acceleration, g's}

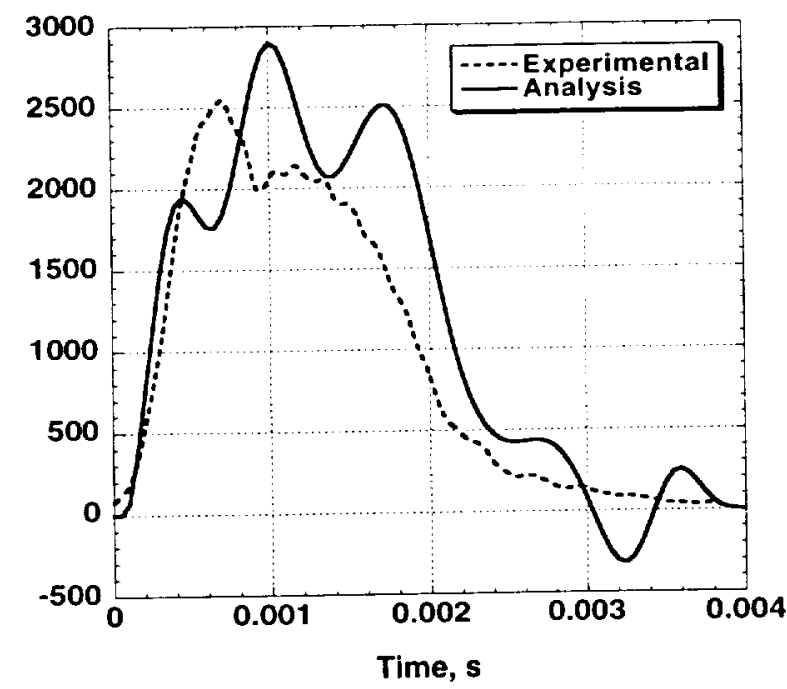

Figure 11 -Comparison of predicted results with experimental acceleration time histories.
The finite element simulation of the impact event predicted a total crush stroke of $0.036 \mathrm{~m}$, or $53 \%$ of the available crush distance of the model. The experimental test showed that the cellular structure experienced a total crush stroke of $60 \%$, or $0.041 \mathrm{~m}$. These results indicate that the numerical model was too stiff. However, the predicted maximum crush stoke was only $12 \%$ lower than the experiment. A deformed plot of the cellular structure is shown in Figure 12.

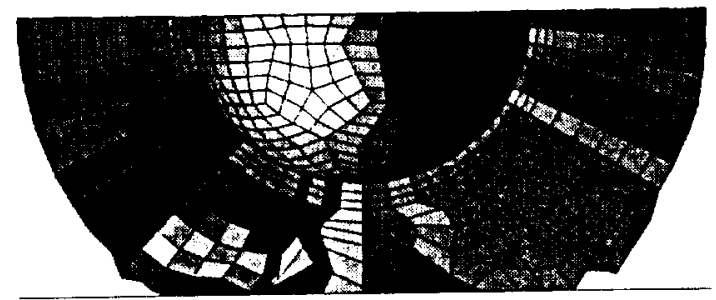

Figure 12 - Cross section of deformed impact structure at $0.002 \mathrm{~s}$ showing maximum crush.

\section{Impact Simulation \#2}

The objective of the second drop test of the impact sphere was to provide additional data for the design of the cellular structure at higher impact speeds more representative of the EEV's terminal velocity. In order to achieve the higher impact velocity, a bungee accelerator was installed under the gantry. The impact velocity of the drop test specimen was targeted to be 40 $\mathrm{m} / \mathrm{s}$ with an actual impact speed of $35.52 \mathrm{~m} / \mathrm{s}$. The drop test specimen was constructed using stronger, higher density polyurethane foam. The total mass of the cellular structure, $\mathrm{CV}$ and $\mathrm{OS}$ was $12.381 \mathrm{~kg}$. The drop test specimen had an outside diameter of $0.314 \mathrm{~m}$ and an inside diameter of $0.154 \mathrm{~m}$, resulting in a cell height of $0.080 \mathrm{~m}$. The thickness of the $\mathrm{CV}$ was $0.0056 \mathrm{~m}$. Two high-g accelerometers were used to capture the impact pulse. One accelerometer was located within the drop test specimen to capture the OS acceleration response. The second accelerometer was mounted on the impact test plate. One low-g accelerometer and footage from digital video were used to determine the impact velocity. For the impact test, the OS acceleration was completely lost due to a failure in the accelerometer-umbilical connection. The acceleration of the plate was captured over the first $0.0025 \mathrm{~s}$, before the cable was severed.

\section{Finite Element Model}

Changes were made to the analytical model to represent the changes made to the drop test specimen and to provide a representative simulation. As before, solid elements were used to discretize the polyurethane foam cores. For the polyurethane foam, an isotropic, 
crushable material with a Poisson's ratio of effectively zero was used. This FOAM1 material model in MSC.Dytran replaced the isotropic, elastic-plastic material model used in the earlier model and allowed for increased plastic deformation of elements during the impact test. A user-defined table was implemented representing the stress-strain data from a quasi-static crush test. Since the Poisson's ratio is effectively zero, only one other elastic constant was needed. For this material, a bulk modulus of $8.21 \times 10^{6} \mathrm{~Pa}$ was defined. The stronger, denser polyurethane foam had a density of $111.514 \mathrm{~kg} / \mathrm{m}^{3}$ and a yield stress of $1.319 \times 10^{6} \mathrm{~Pa}$.

The cell walls of the model were also modified to include a user defined failure criterion that would represent the failure that occurred during the impact test. The failure model in the cell walls was based on a maximum plastic strain criterion, such that the elements in the cell walls will fail once a plastic strain of $25 \%$ is reached.

The overall mass for the second drop test specimen was increased. In the previous model, localized deformations associated with the lumped masses were observed around the top of the finite element model. In order to remove the localized deformation, the concentrated masses were distributed over 30 nodes around the top of the model. Each lumped mass was $0.214 \mathrm{~kg}$, resulting in $6.415 \mathrm{~kg}$ of total mass added to the model.

\section{Numerical Results}

The simulation was executed for $0.004 \mathrm{~s}$ with the impact taking approximately $0.0035 \mathrm{~s}$ before the structure rebounded. This ensured that the entire acceleration pulse was captured by the code. The time step for the simulation stabilized at 0.1593 microseconds. A total run time of approximately 3.5 CPU hours was required on a Sun Ultra Enterprise 450 engineering workstation.

The experimental acceleration response of the plate was plotted and compared with analytical data from the finite element analysis in Figure 13. The plate acceleration data was filtered with a $5,000 \mathrm{~Hz}$ low pass filer. The analysis calculated a peak acceleration of the cellular structure of approximately $2,400 \mathrm{~g}$ 's. The peak acceleration value of the experiment was $2,700 \mathrm{~g}$ 's, a value that was $11 \%$ higher than the analytical trace. However, the pulse shape closely matched the experimental acceleration trace. Even though the test data ends at $0.0025 \mathrm{~s}$, the analytical data was carried out to show the possible response of the cellular structure through rebound.
The total crush stoke predicted by the analysis is 0.054 $\mathrm{m}$ or $80 \%$ of the available crush distance. The simulation showed maximum crush occurred at approximately $0.002 \mathrm{~s}$ after initial inpact. These values compared favorably with the experimental test article, which had a crush stroke of $0.056 \mathrm{~m}$ or $79 \%$ of the available crush distance. Model deformation as calculated by the finite element simulation is shown in Figure 14. A photograph of the test article after impact is shown in Figure 15.

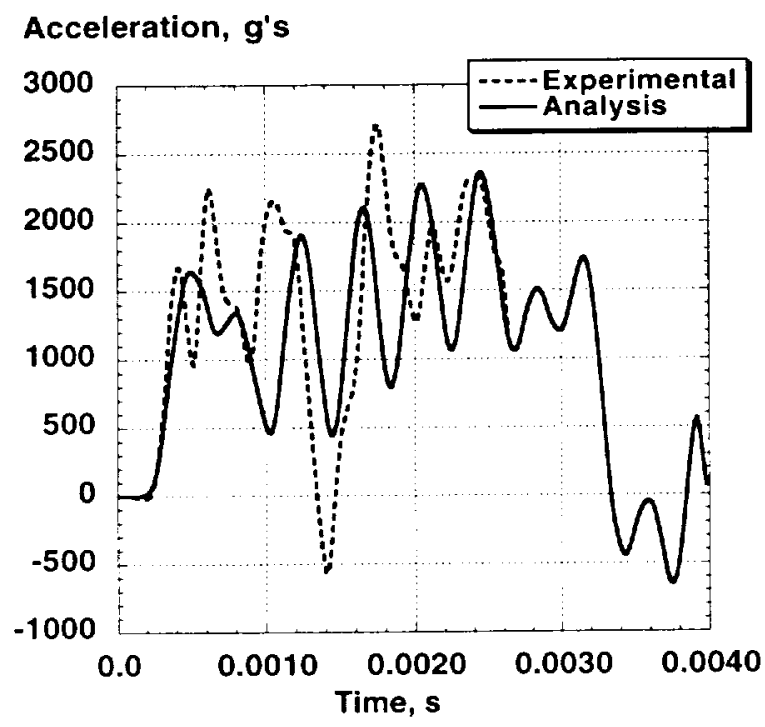

Figure 13 - Predicted acceleration versus experimental acceleration of the impact test ring.

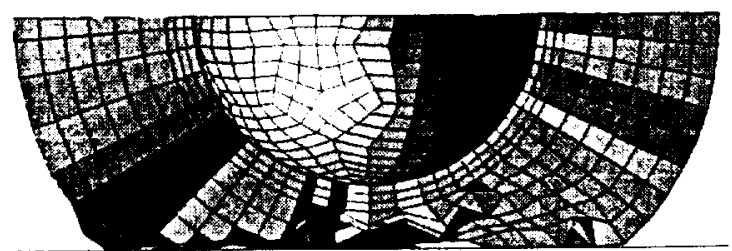

Figure 14 - Cross section of deformed impact structure at maximum crush at $0.002 \mathrm{~s}$.

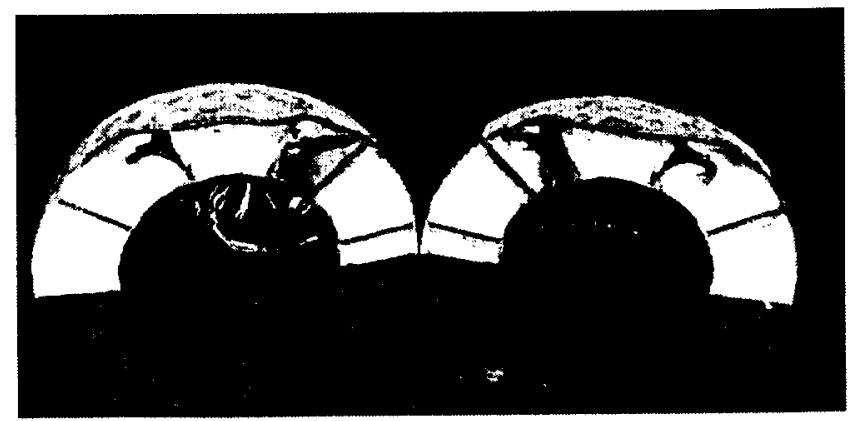

Figure 15 - Bisected cellular structure, post-test. 


\section{Impact Simulation \#3}

The third drop test specimen included a spherical shaped, full scale OS with its own internal data acquisition system. Hardware representing the current dimensions and weight of the $O S$ were delivered from NASA's Jet Propulsion Laboratory (JPL) for insertion into the cellular structure. The $O S$ had an outside diameter of $0.155 \mathrm{~m}$ and had a mass of $3.774 \mathrm{~kg}$. In order to achieve an impact velocity representative of terminal velocity, additional and stiffer bungee cords were used in the bungee accelerator. This change allowed for the impact velocity of the drop test specimen to be increased toward the target of $42 \mathrm{~m} / \mathrm{s}$, with an achieved impact speed of $40.4 \mathrm{~m} / \mathrm{s}$. One high-g accelerometer was mounted on top of the OS to capture the OS acceleration trace. Two high-g accelerometers were located on the impact test plate to measure the plate acceleration. There was also a JPL supplied high$\mathrm{g}$ accelerometer located within the $O S$ at the approximate CG. Additionally, one low-g accelerometer was used to determine the impact velocity. Digital video was used to capture the test.

The design of the drop test specimen was also modified to closely resemble the final design. The polyurethane foam was replaced by carbon foam, which is better suited for space applications due to low out-gassing, a higher stiffness to weight ratio, and structural integrity at higher reentry temperatures. The amount of Kevlar that was wrapped around the outside of the cellular structure was increased to approximately $0.002083 \mathrm{~m}$. The graphite-epoxy laminate that lined the inner surface of the cellular structure was also increased to 8 layers, or $0.002032 \mathrm{~m}$. The thickness of the cell walls were increased by adding additional layers of graphite-epoxy and Kevlar, providing 18 layers for each cell wall, or $0.004572 \mathrm{~m}$. The thickness of the $\mathrm{CV}$ was approximately $0.0048 \mathrm{~m}$. The mass of the cellular structure, CV, OS, and the impact test plate was 14.22 $\mathrm{kg}$. The cellular structure has on outside diameter of $0.308 \mathrm{~m}$ and an inside diameter of $0.172 \mathrm{~m}$, resulting in a height of $0.068 \mathrm{~m}$ for the cells.

\section{Finite Element Model}

A more detailed model was constructed to represent the more detailed drop test specimen. The cellular structure and impact surface were modeled in the same manner as in the previous drop test articles. However, the design changes for this test were incorporated into the finite element model. The polyurethane foam was replaced with carbon foam and modeled with a FOAMI material model. The user defined stress-strain table was modified from previous models to match crush data provided from carbon foam penetration tests ${ }^{4}$. The density $\rho$ of the carbon foam was $57.656 \mathrm{~kg} / \mathrm{m}^{3}$ and a bulk modulus $\mathrm{G}$ of $4.6 \times 10^{7} \mathrm{~Pa}$ was defined. Additional layers of graphite, graphite-epoxy, and Kevlar were added to the concept resulting in a greater thickness for most of the defined shell elements. The 4-noded shell elements that represented the graphite-epoxy/Kevlar cell walls, the Kevlar outer skin, and the graphite-epoxy inner surface were increased in thickness to match the drop test specimen.

In addition to these modified components, an OS and impact test plate were geometrically modeled and added to the existing model. By including these two components, the overall complexity of the model increased and the analysis became more difficult. A complete detailed model is shown in Figure 16. A cross section of the finite element model is shown in Figure 17.

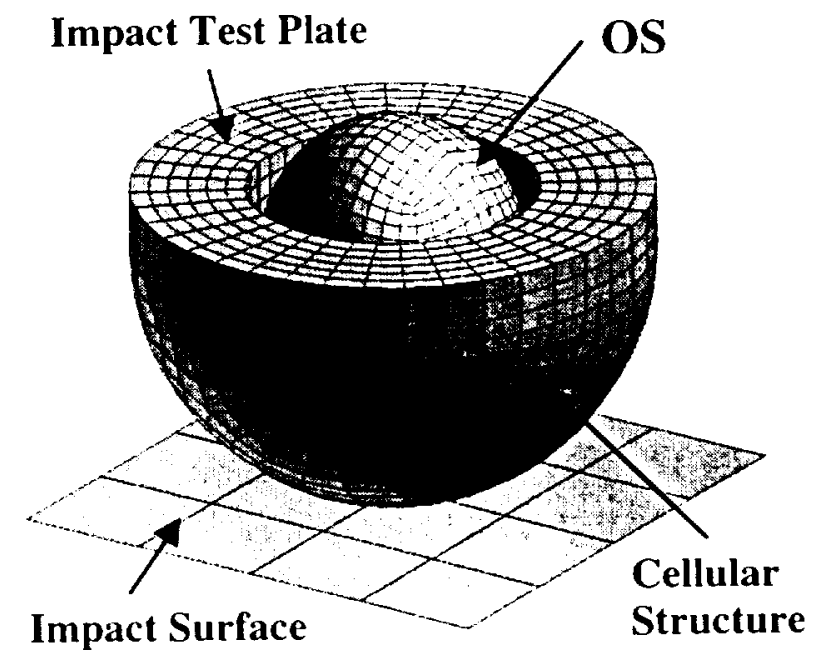

Figure 16 Components of higher fidelity, finite element model.

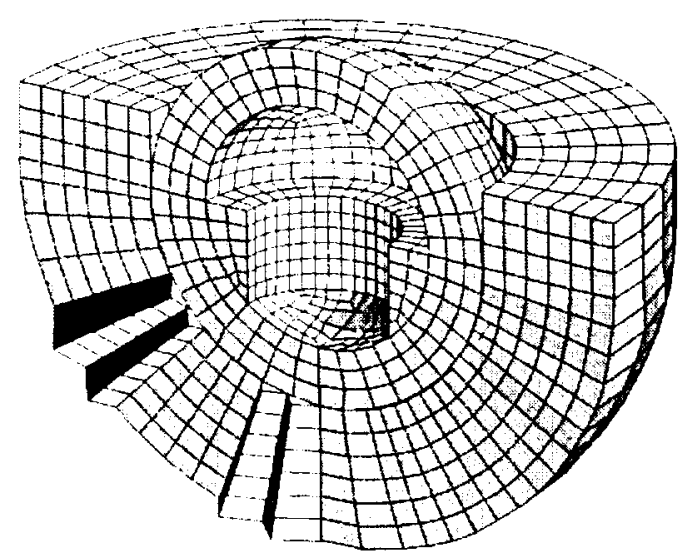

Figure 17 - Cross-section of detailed finite element model. 
The complete OS was modeled using 3,528 grid points and 3,560 elements. Of those 3,560 elements, the inner surface of the OS was modeled with 840 4-noded Lagrangian shell elements. The shell elements were used to represent the inner surface of the OS and are modeled as a rigid body. The rigid body represents the titanium canister that is used to store the collected samples over the course of the mission. For this drop test, the mass of the inner surface of the OS was 1.76 $\mathrm{kg}$. Also defined on the MATRIG material card is the impact velocity for this test, $40.4 \mathrm{~m} / \mathrm{s}$.

Surrounding the rigid shells are the 2,720 8-noded, single integration point, Lagrangian solid elements that represent the foam used in the OS. The material model for these elements is an isotropic, elastoplastic material model with a yield stress defined to allow for plastic deformation. The density $\rho$ of the foam used in the OS was $460 \mathrm{~kg} / \mathrm{m}^{3}$, the Young's modulus $E$ was $4.38 \times 10^{8}$ $\mathrm{Pa}$, the Poisson's ratio $v$ was 0.334 , and the yield stress was $1.54 \times 10^{7} \mathrm{~Pa}$.

The impact test plate was modeled using 871 nodes and 720 8-noded Lagrangian solid elements. An isotropic, elastoplastic material model was used to define the impact test plate. For this drop test, the mass that was added to the top of the cellular structure was $4.25 \mathrm{~kg}$, which resulted in a density $\rho$ of the impact test plate of $4,630 \mathrm{~kg} / \mathrm{m}^{3}$. The Young's modulus $E$ of the impact test plate was $2.72 \times 10^{10} \mathrm{~Pa}$, the Poisson's ratio $v$ was 0.3 , and the yield stress was $2.68 \times 10^{8} \mathrm{~Pa}$.

\section{The Two Body Interaction}

The CV provides the coupling between the OS and the cellular structure. The measured accelerations at the top of the OS and on the top surface of the impact test plate above the cellular structure and OS are shown in Figure 18. Note that there is a time delay of approximately $0.0005 \mathrm{~s}$ from the beginning of the impact test plate acceleration to the initiation of the OS acceleration. This delay is due to the highly nonlinear CV material, which fills the gap between the OS and the cellular structure. In addition, the relatively large spikes at the end of the traces of the impact test plate and the OS are due to impact of the OS with the impact test plate. Consequently, to evaluate the actual dynamic response of the cellular structure and to remove the interaction between the two bodies, the following equation was developed,

$$
F(t)=A_{C S} M_{C S}+A_{O S} M_{O S}=M_{\text {TOTAL }} A_{A V G}
$$

Where $F(t)$ is the crush force of the cellular structure, $A_{C S}$ is the acceleration of the cellular structure with its attached structure on top, $A_{O S}$ is the acceleration of the
$\mathrm{OS}$, and $\mathrm{A}_{\mathrm{AVG}}$ is the average acceleration of the system (or the acceleration at the $\mathrm{cg}$ of the system).

Solving for the average acceleration:

$$
A_{A V G}=\left(A_{C S} M_{C D}+A_{O S} M_{O S}\right) / M_{\text {TOTAL }}
$$

For the equation to apply, it was assumed that the impact test plate is rigidly attached to the cellular structure and that the mass of the crushed portion of the sphere is small compared with the total mass. By using the average acceleration, the peaks due to the two separate bodies are eliminated, and thus a better representation of the behavior of the cellular structure for a "perfect CV coupling" is obtained. Consequently, the $\mathrm{CV}$ was incorporated in the OS model by coupling the $O S$ to the cellular structure with equivalent nodes. Additionally, since the response of the $\mathrm{CV}$ is highly nonlinear and difficult to model, this approach makes the simulation less complicated.

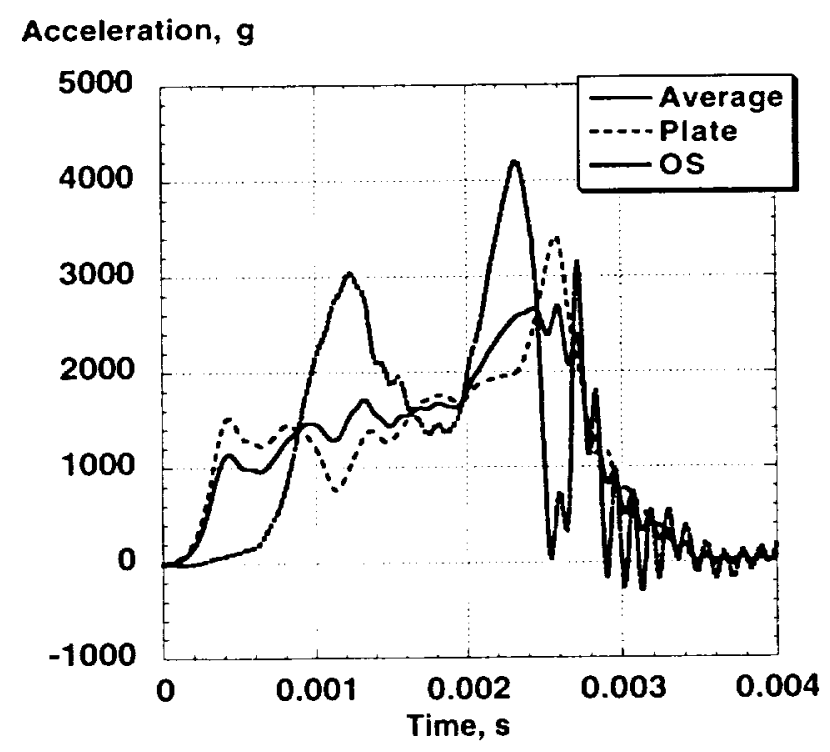

Figure 18 - Experimental accelerations of the OS and impact test plate.

Numerical Results and Discussion

The simulation was run for $0.004 \mathrm{~s}$ to ensure that the complete acceleration pulse was calculated. The time step of the detailed model stabilized at 0.665 microseconds, and the model begins to rebound at approximately $0.0035 \mathrm{~s}$. A total run time of one CPU hour was required to compute the 0.004 second impact scenario on a Sun Ultra Enterprise 450 engineering workstation.

The analysis predicted a peak average acceleration of approximately $2,600 \mathrm{~g}$ 's which occurred at 
approximately $0.0025 \mathrm{~s}$ into the impact simulation. This result compares well with the experimental peak average acceleration of $2,700 \mathrm{~g}$ 's. Overall the simulation accurately predicted the shape, magnitude, and duration of the average experimental acceleration pulses, as shown in Figure 19.

The total crush stroke of the finite element simulation was $0.064 \mathrm{~m}$, or approximately $90 \%$ of the available crush distance. The amount of crush the cellular structure test specimen underwent during the impact test is difficult to measure and is estimated to be from $75 \%$ to $85 \%$ (between $0.051 \mathrm{~m}$ and $0.058 \mathrm{~m}$ ). A deformed plot of the finite element model showing the maximum possible stroke is shown in Figure 20 . A photograph of the cellular structure after the impact is shown in Figure 21.

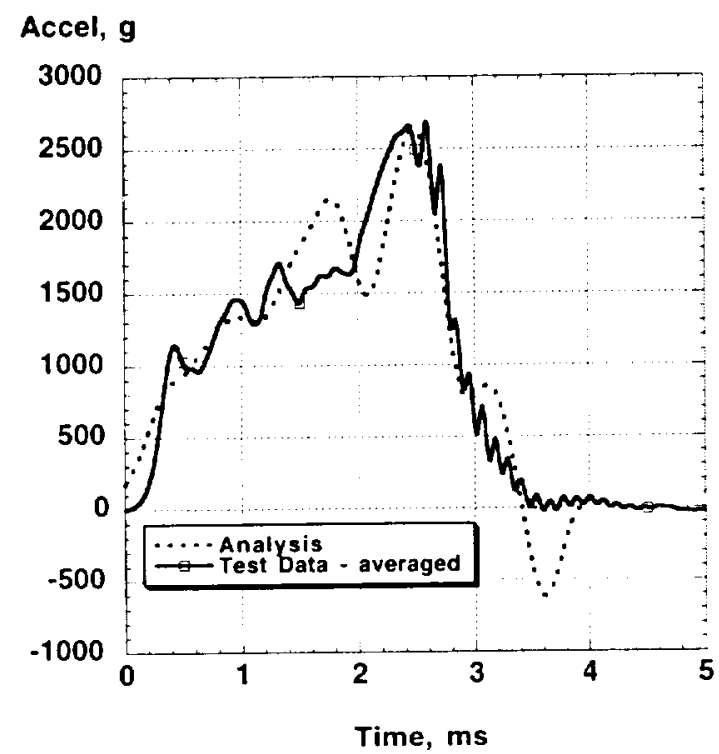

Figure 19 - Comparison of predicted acceleration with average experimental acceleration of impact sphere.

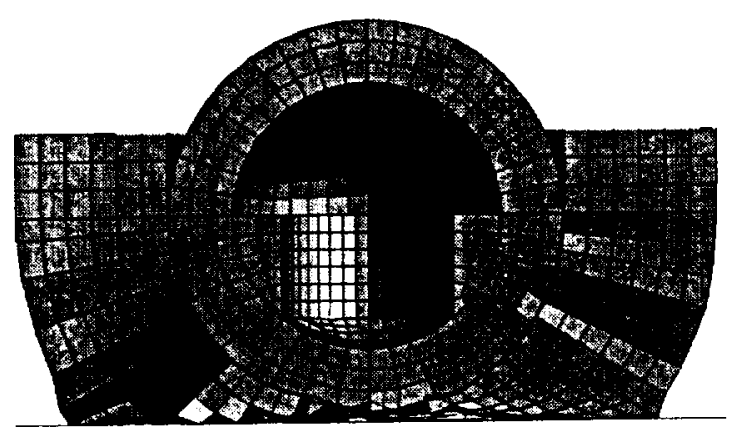

Figure 20 - Deformed plot from finite element simulation showing max crush at $0.003 \mathrm{~s}$

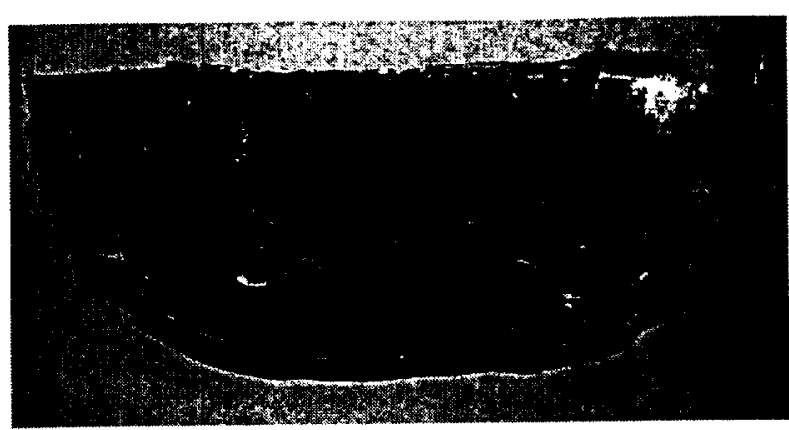

Figure 21 - Bisected mage of the cellular structure, post test.

\section{Summary}

Nonlinear transient dynamic finite element simulations have been performed to aid in the design of energy absorbing concepts for highly reliable, passive, Earth Entry Vehicles (EEV) that impact the Earth without the aid of a parachute. The current concept of the energy absorbing impact sphere is a composite cellular structure made with energy absorbing materials that will limit the acceleration of the samples and ensure containment. Experimental tests were performed for impacts of 32,35 , and $40 \mathrm{~m} / \mathrm{s}$ at the Impact Dynamics Research Facility (IDRF) at NASA Langely Research Center. These simulations have been performed using the nonlinear transient dynamics finite element code MSC.Dytran.

For each impact test, a finite element model was created to accurately represent the cellular structure drop test specimen. Analytical simulations compared favorably with impact test results for the three cellular structures. The analysis predicted the shape, peak, and duration of the experimental acceleration and total crush well.

The material model for the foam elements and the proper failure criteria proved crucial to accurately predict the impact loads on the $O S$ and cellular structure. It was determined that using a FOAMl model for the foam and a $20 \%$ failure strain criteria for the cell walls produced an accurate prediction of the acceleration pulse.

When the cellular structure and OS are modeled separately, the acceleration of each component is complicated due to a two-body interaction. To make meaningful comparisons between analysis and test, a mass-weighted average acceleration of the cellular structure and OS was used. This comparison allowed the acceleration response of the drop test specimen to be determined for a "near perfect" coupling between the OS and cellular structure. 
Analytical models, once verified, will prove useful as a tool for early analysis in the future design and analysis of the cellular structure. In addition, parametric studies of off-nominal impact conditions can be simulated at minimal costs to increase the level of confidence of the concept.

\section{Acknowledgement}

The authors wish to thank Dr. Robert A. Mitcheltree of NASA Langely Research Center for overall program direction, and Dr. Sotiris Kellas of Veridian Systems for information and support pertaining to the design and testing of the cellular structures and for material property data. The work performed by the first author was sponsored by NASA Langley Research Center under NASA Cooperative Agreement NCC1-331.

\section{References}

1. Mitcheltree, R. A. and Kellas, S., "A Passive Earth-Entry Capsule for Mars Sample Return," Symposium on Atmospheric Reentry Systems, Arcachon France, March 1999.

2. Fasanella, E. L.; Jones, Y. T.; Knight, Jr., N. F.; and Kellas, S.: Low Velocity Earth-Penetration Test and Analysis, AIAA paper $2001-1288,42^{\text {nd }}$ Structures, Structural Dynamics, and Materials Conference, Seattle, WA, April 2001.

3. MSC.Software Corporation, "MSC.Dytran Version 4.7 User's Manual," Volumes 1 and 2, Los Angeles, California, 1999.

4. Kellas, S., "Design Fabrication and Testing of a Crash Energy Absorber For a Passive Earth Entry Vehicle", NASA CR To Be Published 2001.

5. Vaughan, V.L. and Alfaro-Bou, E., "Impact Dynamics Research Facility for Full-Scale Airccraft Crash Testing," NASA TN D-8179, April 1976 